\title{
UNDERSTANDING THE CHAOTIC BEHAVIOR OF PARTICULATE MATTER CONCENTRATIONS USING NONLINEAR TECHNIQUES
}

\author{
GIOVANNI ANGELO SALINI \\ Department of Applied Mathematics and Physics, Catholic University of Concepción, Chile
}

\begin{abstract}
We have made a comparative study about the nonlinear behaviour of $\mathrm{PM}_{2.5}$ hourly average concentrations, which were measured at some of the most polluted mid-sized cities located in the South of Chile. The chosen cities were Chillán, Coyhaique and Temuco where high $\mathrm{PM}_{2.5}$ concentrations concentrated in the winter season are caused by the intensive use of wood for heating. The city of Cochabamba, Bolivia, has also been included in this study, due to its very high level of atmospheric pollution by $\mathrm{PM}_{10}$ (especially in the winter season). This city is at a greater height compared to the Chilean cities. Using nonlinear tools, as Wavelet, Recurrence Plots, and Phase Portrait we have investigated the behaviour of $\mathrm{PM}_{2.5}$ and $\mathrm{PM}_{10}$ (hourly) concentrations. Wavelet spectrum and global amplitude for the more polluted cities in study was calculated. Spectral descomposition was performed in time-frecuency through Morlet's wavelet transform and their global amplitud in time and energy, concentrated around the most importants peaks. On the other hand, a graphical tool that shows typical patterns of dynamic behaviour is the recurrence graph allowing extraction of qualitative characteristics from time series. This method was applied for all cities in study showing patterns that differ from a noisy or random signal. Also the technique of phase-portrait analysis was implemented, showing typical dynamical patterns of non-linear time series, different to a noisy signal pattern. Finally, it was found that hourly airborne particle concentrations exhibit a possible chaotic behaviour, related to short-term predictability some hours ahead.
\end{abstract}

Keywords: PM 2.5 , wavelet, recurrence plots, phase portrait, AMI, FNN.

\section{INTRODUCTION}

Air pollution (e.g. $\mathrm{SO}_{2}, \mathrm{NO}_{\mathrm{x}}, \mathrm{PM}_{2.5}, \mathrm{O}_{3}$, etc.) has been a major concern after the evidence that the level of pollution is strictly associated with the health of human beings. Especial attention has received $\mathrm{PM}_{10}$, particulate matter (PM) with diameter up to $10 \mu \mathrm{m}$. This pollutant reaches significantly high concentrations in the metropolitan area of Santiago, the capital of Chile and has been a matter of concern for authorities during the last 30 years. Between April and August, dispersion of atmospheric pollutants in the valley is poor, which is related to strong surface thermal inversions, associated to anticyclone conditions at a regional scale. During this period of the year, frequent episodes with high concentrations of $\mathrm{PM}_{10}$ are observed and some restrictions to sources of emission are imposed. Epidemiological studies indicate also that concentrations of fine particulate matter (particles with aerodynamic diameter less than $2.5 \mu \mathrm{m}, \mathrm{PM}_{2.5}$ ) have considerable impact on human health, even at concentrations below the present ambient air quality standards. These particles are more harmful than coarse particulate matter [1]-[3]. $\mathrm{PM}_{2.5}$ particles can penetrate the respiratory tract and have toxic effects in heart (Brook et al. [4]), cardiovascular disease (Lee et al. [5]) and lungs [6]-[8]. The main sources of PM are the vehicular traffic, dust of the streets generated by the circulation, and emissions from wood stoves.

Very few countries have a $\mathrm{PM}_{2.5}$ standard. In the United States, a 24-h $\mathrm{PM}_{2.5}$ standard of

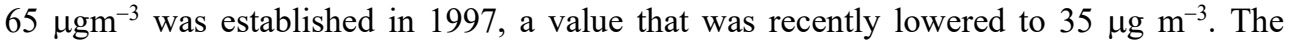
standard for the annual average is $15 \mu \mathrm{g} \mathrm{m}^{-3}$. The World Health Organization (WHO) has recently recommended that in order to avoid significant harmful effects in the population, the 
$\mathrm{PM}_{2.5}$ 24-h average should not exceed $25 \mu \mathrm{g} \mathrm{m}^{-3}$ and that the annual average must not exceed $10 \mu \mathrm{g} \mathrm{m}^{-3}$ [9]. Since January 2012, Chile has a $\mathrm{PM}_{2.5}$ standard. 24-h average standard is 50 $\mu \mathrm{g} \mathrm{m}^{-3}$ and the annual average should not exceed $20 \mu \mathrm{g} \mathrm{m}^{-3}$ [10]. Concentrations of $\mathrm{PM}_{2.5}$ not only in Santiago but in several mid-sized cities, especially from South of Chile, often exceed the recommended maximum levels. These exceedances are concentrated during the period between April and August indicating a clear seasonal fall-winter effect. In this period, strong thermal inversions are observed (which do not occur in spring and summer). The main source of $\mathrm{PM}_{2.5}$ emissions in mid-sized city, is the intense use of wood stoves for heating in winter. Cities like Chillán, Temuco and Coyhaique, have experienced severe short-term pollution events that are harmful to human health. (For more details on mid-sized Chilean cities, see Salini [11]).

Bolivia has an environmental regulation promulgated in the year 1992 [12]. According to this law, limit concentration for diameter particles smaller than $10 \mu \mathrm{m}\left(\mathrm{PM}_{10}\right)$ is $150 \mu \mathrm{g} \mathrm{m}^{-3}$ for $24 \mathrm{~h}$ and $50 \mu \mathrm{g} \mathrm{m}^{-3}$ for the annual average. Salini and Medina have performed a study of $\mathrm{PM}_{10}$ time series analyzing the poor air quality at Cochabamba city through statistical tools used in studies on nonlinear dynamics [13]. The daily average of $\mathrm{PM}_{10}$ follows patterns similar to large cities with high of environmental pollution patterns. One of the parameters resulted from the same order and characteristic as those presented in similar studies on the chaos in pollution variables such as ozone, $\mathrm{PM}_{2.5}, \mathrm{CO}$, demonstrating the chaotic origin of these data.

In this paper, the author uses a different nonlinear approach in order to support the fact that air pollution is a complex and nonlinear dynamic system (Sprott [14]). The author has analyzed $\mathrm{PM}_{2.5}$ time series in mid-sized cities, from South of Chile and $\mathrm{PM}_{10}$ from Cochabamba, Bolivia, during recent years and have calculated relevant nonlinear parameters. The complexity of such time series has made its interpretation very difficult. The aim of this study was to explore the relation between complexity and chaos theory based on the particulate matter concentration, applying wavelet tools to $\mathrm{PM}_{2.5} / \mathrm{PM}_{10}$ time series concentrations and displayed the results obtained by these techniques. Recurrence plots and phase space are other type of mathematical tools applied to such time series. The author has applied nonlinear mathematical tools successfully in previous works (Salini and Pérez [15], Salini and Pérez [16], Salini and Medina [13]). The results obtained through these new methodologies give rise to the application of more advanced tools that give light on the complexity of these time series consisting of particulate matter concentrations, such as Recurrence Quantification Analysis (RQA). This work is part of research project DIN13/2016.

\section{STUDY AREA AND DATA DESCRIPTION}

\subsection{The data}

For all three chilean cities the available data covers a period of ten years between 2007 and 2016. $\mathrm{PM}_{2.5}$ time series concentration consisting of hourly databases and were collected from MACAM III monitoring systems of SINCA (Chilean Air Quality Information System, [17]) depending of the Ministry of Health, being maintained by the Chilean Ministry of the Environment [18]. The monitoring station at Chillán was Purén; Museo Ferroviarion was the monitoring station for Temuco, and Coyhaique II for Coyhaique (Fig. 1).

For Cochabamba, the $\mathrm{PM}_{10}$ hourly databases are from 2009 to 2012, available from Kanata Park station. It was obtained from the MoniCA Network system [19] and the Bolivian Ministry of Environment and Water [20]. 


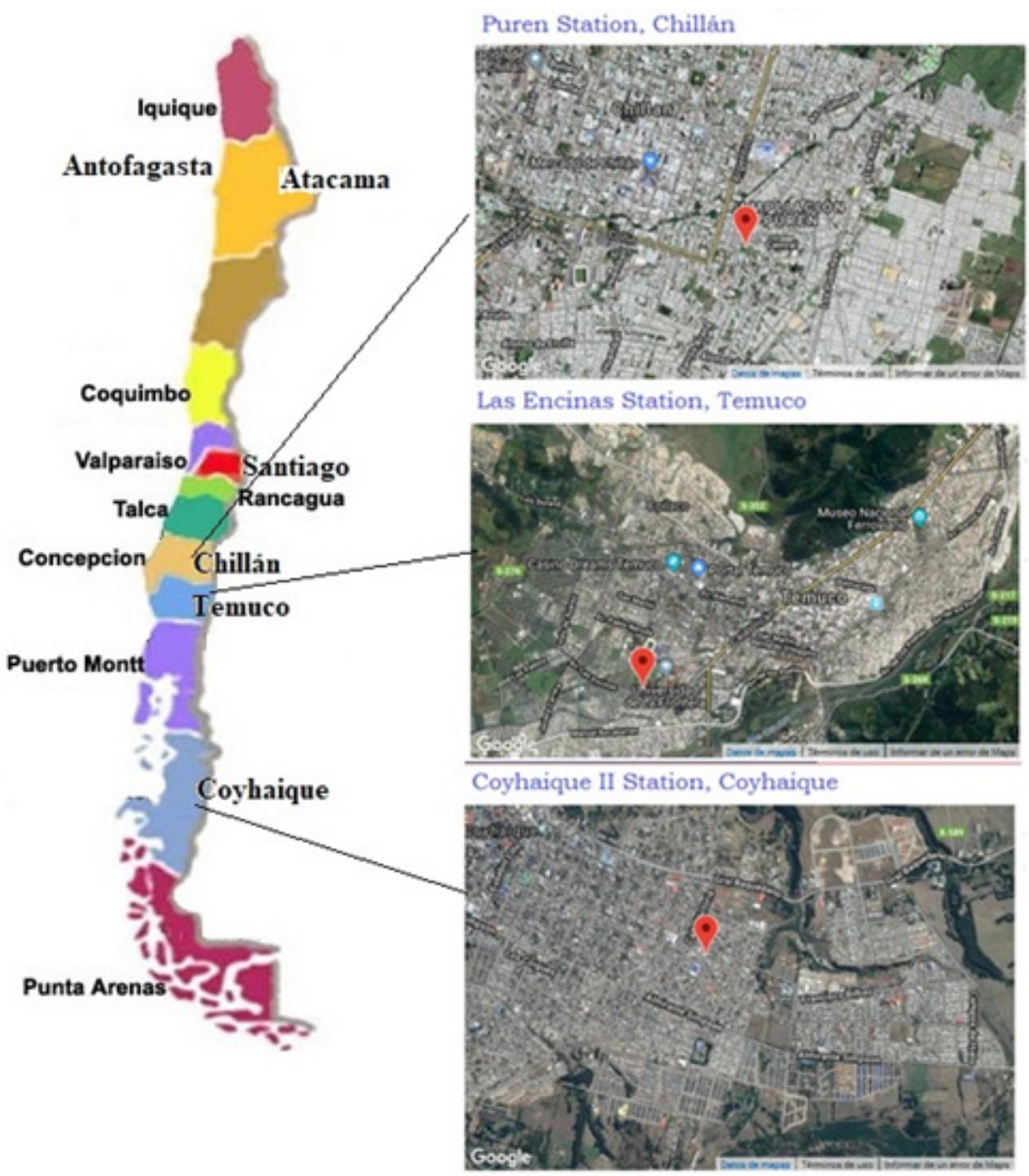

Figure 1: Location of $\mathrm{PM}_{2.5}$ monitoring stations in cities localized at South of Chile. (Source: adapted from [18].)

\subsubsection{The Chilean cities}

The cities under study were the most polluted from South of Chile, and Table 1 shows the detailed information about these three cities, where we can see the data of annual average of $\mathrm{PM}_{2.5}$ (2015).

\subsubsection{The Bolivian city}

The city of Cochabamba lies between $17^{\circ} 23^{\prime}$ south latitude and $66^{\circ} 9^{\prime}$ west longitude of the Greenwich Meridian, located at a height of $2558 \mathrm{~m}$ a.s.l. being located in the center of the 
country [13]. It is furrowed by the Eastern branch of the Mountain range of The Andes Mountains, located in the valley of the same name, being capital of the Department of Cochabamba and the province of Cercado, Fig. 2. It has a population of 616021 inhabitants, in an area of approximately $55631 \mathrm{~km}^{2}$.

\section{METHODOLOGY}

Three methods have been applied to analysis $\mathrm{PM}_{2.5}$ and $\mathrm{PM}_{10}$ concentration: wavelet, phase space and recurrence plots. In all three methods average mutual information (AMI) was evaluated for determining the lag $(\tau)$ and False Nearest Neighbours (FNN) for determining the embedding dimension $(m)$ because of the non-linear nature of particulate matter concentration [15], [16].

\subsection{Wavelet}

Wavelet analysis (Mallat [21], Torrence and Compo [22]) is a particular time- or space-scale representation of signals which has found a wide range of applications in physics, geophysics, signal processing and applied mathematics in the last years.

Table 1: Geopolitical information of cities in Southern Chile. (Source: adapted from [14].)

\begin{tabular}{|c|c|c|c|c|c|c|}
\hline City & Lat. $\left(^{\circ}\right)$ & Lon. $\left(^{\circ}\right)$ & Region & $\begin{array}{c}\text { Elevation } \\
(\mathrm{m} \text { a.s.1. })\end{array}$ & Population & $\begin{array}{c}\mathrm{PM}_{2.5} \\
\left(\mu \mathrm{g} \mathrm{m}^{-3}\right)\end{array}$ \\
\hline Chillán & $\begin{array}{c}36^{\circ} 36^{\prime} \\
24^{\prime \prime} \mathrm{S}\end{array}$ & $72^{\circ} 6^{\prime} 12^{\prime \prime} \mathrm{W}$ & Bío Bío & 124 & 175.869 & 32 \\
\hline Temuco & $\begin{array}{c}38^{\circ} 44^{\prime} 0^{\prime \prime} \\
\mathrm{S}\end{array}$ & $72^{\circ} 36^{\prime} 0^{\prime \prime} \mathrm{W}$ & Araucanía & 122 & 260.878 & 33 \\
\hline Coyhaique & $\begin{array}{c}45^{\circ} 34^{\prime} 0^{\prime \prime} \\
\mathrm{S}\end{array}$ & $72^{\circ} 04^{\prime} 0^{\prime \prime} \mathrm{W}$ & Aisen & 310 & 82.071 & 55 \\
\hline
\end{tabular}

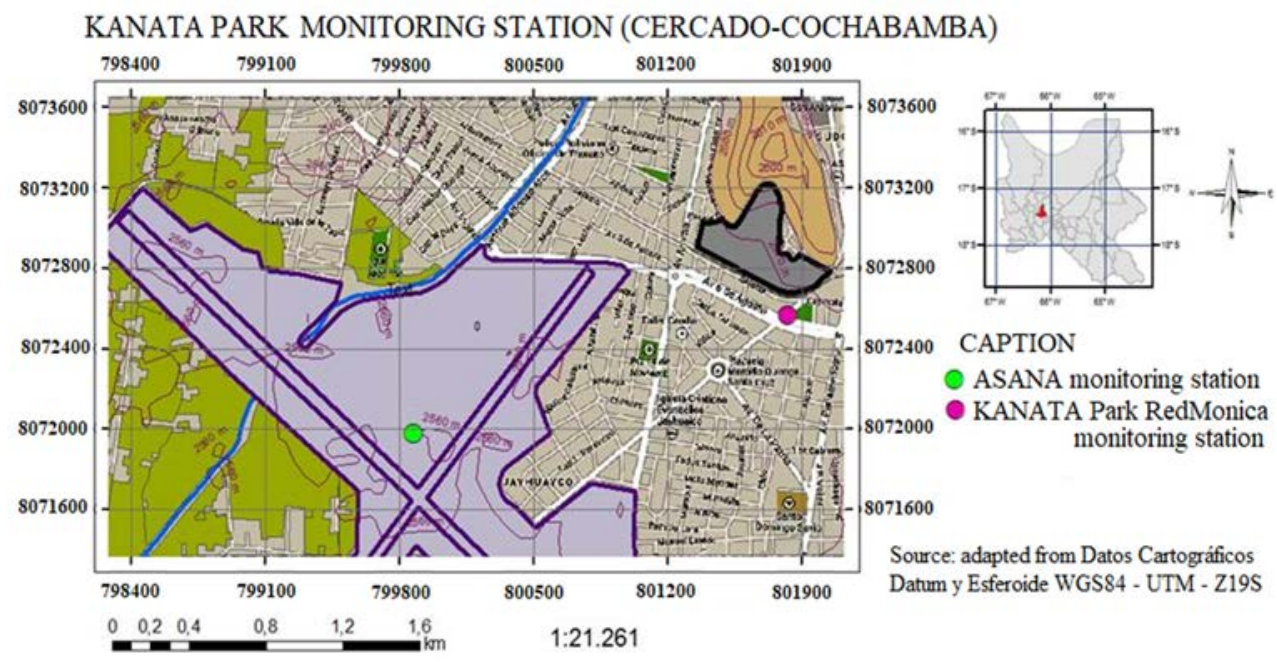

Figure 2: Location of $\mathrm{PM}_{10}$ monitoring stations in Cochabamba urban area. (Source: adapted from [13].) 
Let $\mathrm{x}(\mathrm{t})$ be a time series and $\Psi_{\mathrm{a}, \mathrm{b}}$ a wavelet (real or complex) defined by

$$
\Psi_{a, b}=\Psi_{0}\left(\frac{t-b}{a}\right)
$$

where a is a dilatation control if $a>1$ or contraction if a $<1$ of $\Psi_{0}$ function, and $b$ is a temporary displacement variable.

The continuous wavelet transform is defined as the convolution between $\mathrm{x}(\mathrm{t})$ and $\Psi_{\mathrm{a}, \mathrm{b}}$ given by

$$
T(a, b)=\frac{1}{\sqrt{a}} \int_{-\infty}^{\infty} x(t) \Psi_{0}^{*}\left(\frac{t-b}{a}\right) d t
$$

where $\Psi_{0}{ }^{*}$ is the conjugate complex of $\Psi_{0}$ and $1 / \sqrt{ }$ a is the normalization factor for $\Psi_{0}$.

Most real-life signals are nonstationary and cover a wide range of frequencies. Standard Fourier analysis is inadequate for treating such signals, since it loses all information about the time localization of a given frequency component.

Wavelet transform can be used to analyze time series pollution that contain nonstationary power at many different frequencies. Morlet wavelet is used to analyze $\mathrm{PM}_{10} / \mathrm{PM}_{2.5}$ time series, consisting of a plane wave modulated by a Gaussian:

$$
\psi_{0}(v)=\pi^{-1 / 4} e^{i \omega_{0}} e^{-v^{2} / 2},
$$

where $\omega_{0}$ is the dimensionless frequency.

\subsection{Phase portrait}

The fundamental starting point of many approaches in nonlinear data analysis is the construction of a phase space portrait of the considered system. The state of a system can be described by its state variables

$$
\{x(i)\}_{i=1}^{d}
$$

The $d$ state variables at time $\mathrm{t}$ form a vector in a $d$-dimensional space which is called phase space. The state of a system typically changes in time, and, hence, the vector in the phase space describes a trajectory representing the time evolution (the dynamics of the system). The shape of the trajectory gives hints about the system; periodic or chaotic systems have characteristic phase space portraits [13]. The observation of a real process usually does not yield all possible state variables. Either not all state variables are known or not all of them can be measured. However, due to the couplings between the system's components, we can reconstruct a phase space trajectory from a single observation $u_{i}$ by a time delay embedding. Takens' theorem statement that it is possible to reconstruct the original phase-space of a dynamical system from embedding vectors, eqn (5), of univariate measurements of the system state, if the embedding dimension $m$ is sufficiently greater than the dimension of the underlying system. (Takens [23]). This reconstruction of the phase space is called time delay embedding. The phase space reconstruction is not exactly the same to the original phase space, but its topological properties are preserved, if the embedding dimension is large enough (the embedding dimension has to be larger than twice the phase space dimension, or 
exactly $m>2 d+1)$. And this reconstructed trajectory is sufficient enough for a subsequent analysis [24], [25].

\subsection{Recurrence plots}

Recurrence plot is a graphical tool (Eckmann et al [26]) that depict the different occasions when dynamical systems visit the same region of phase space, extracting qualitative characteristics of a time series (of a simple observable variable, as particulate matter, in this case). The recurrence of a state $i$ at a different time $j$ is pictured within a 2-dimensional squared matrix with white and black dots, where both axes represent time, and black dots represent a recurrence of a system.

Given a scalar time series, as eqn (4), a recurrence plot is constructed by first embedding the time series into a multi-dimensional space of vectors whose coordinates are present and lead values of the series,

$$
y(i)=\{x(i), x(i+\tau), x(i+2 \tau), \ldots, x(i+(m-1) \tau)\}^{T},
$$

where $m$ is the embedding dimension and $\tau$ is the time delay. Then, mathematically a recurrence plot (RP) is expressed as:

$$
R_{i j}(\varepsilon)=\left\{\begin{array}{l}
0, \text { if }\|y(i)-y(j)\|>\varepsilon \\
1, \text { if }\|y(i)-y(j)\| \leq \varepsilon
\end{array} \quad \forall i, j=1,2, \ldots, n, n=N-(m-1) \tau\right.
$$

where $\varepsilon$ is a threshold distance, $\|\cdot\|$ a norm (usually Euclidean), $\mathrm{N}$ the number of state considered. From this definition, it is observed that $\mathrm{R}_{\mathrm{ii}}=1(\mathrm{i}=1, \ldots, \mathrm{N})$ and the $\mathrm{RP}$ has a black diagonal line called line of identity. In addition, RP are symmetrical with respect the line of identity, because $\mathrm{R}_{\mathrm{ij}}=\mathrm{R}_{\mathrm{ji}}$. Then, patterns formed by adjacent recurrence points show evidence of determinism and periodicity in the system. On the other hand, diagonal lines parallel with the line of identity occur when segments of the trajectory visit the same region of the phase space at different time, being the length of these lines determined by the duration of these visit. Horizontal and vertical lines suggest stationary states (the system persist in the same region). Isolated recurrence points may occur when states are rare, showing large fluctuations or little persistency. Finally, deterministic systems tend to present long diagonal lines and few isolated points. However, stochastic systems present mostly isolated points and very short diagonal lines [27]-[30].

\section{RESULTS AND DISCUSSION}

\subsection{Phase space}

Fig. 3 shows 3-D projections of the state space trajectories obtained from the $\mathrm{PM}_{2.5}$ and $\mathrm{PM}_{10}$ time series pollution. The Fig. correspond to attractor in 3-D embedding phase-space reconstructed for each time series concentrations. These plots are typical of chaotic systems.

The phase space plots for noise almost fill all state space. These results are similar to that in [13] and [16].

Chelani et al. [31] performed a careful investigation of the space space of $\mathrm{NO}_{2}$ concentration at industrial, residential and commercial sites - in Kolkata, India- founding similar results to the author. On the other hand, Aceves-Fernandez et al. [30] applied 


\section{PM2.5 time-delay embedding - Phase Space Plot \\ Puren station, Chillán, 2015}

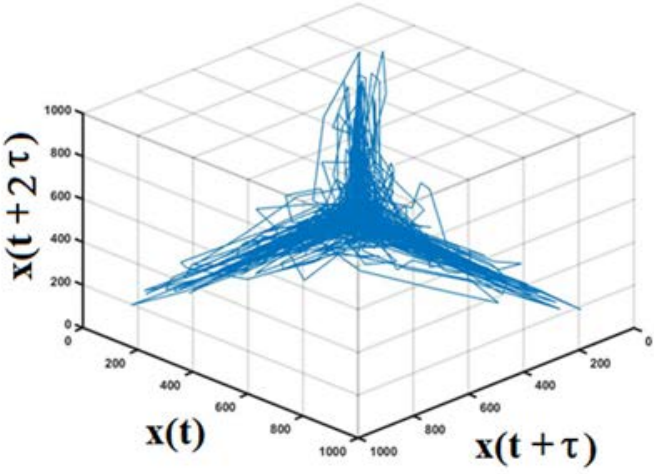

\section{PM10 time-delat embedding - Phase Space Plot Kanata Park station, Cochabamba, 2011}

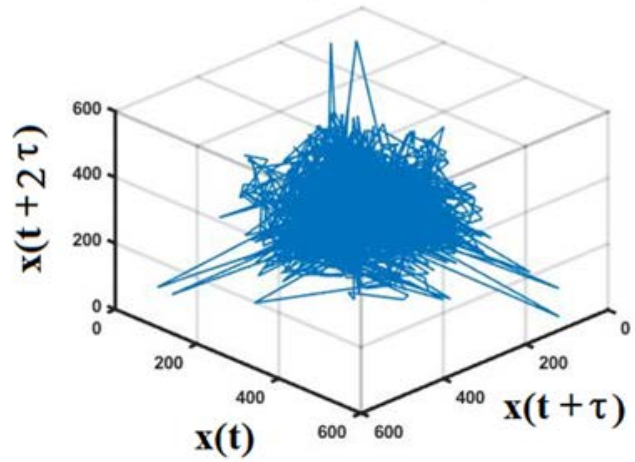

Figure 3: Phase Space of $\mathrm{PM}_{2.5}$ for monitoring station in Chillán urban area and $\mathrm{PM}_{10}$ monitoring stations in Cochabamba urban area.

recurrence plots to different gases and $\mathrm{PM}_{10}$ at Mexico City, finding similar result to the author, which can see in Fig. 4. Therefore, the pattern generated using our methodology are similar to [30]. It would be interesting to apply a quantitative method to this type of tool, to have more certainty of the results obtained quantitatively, as recurrence quantitative analysis (RQA) or another type of equivalent tool.

\subsection{Recurrence plots}

Fig. 4 presents recurrence plots for $\mathrm{PM}_{2.5}$ for monitoring station of cities from South of Chile, and $\mathrm{PM}_{10}$ Parque Kanata monitoring stations in Cochabamba urban area. According to 3.3 section, these plots show evidence of determinism and quasi-periodicity in the system, because they tend to display long diagonal lines and few isolated points. From the other hand, stochastic system and noise data present mostly isolated points and very short diagonal lines. Then, our pollution series present signs of chaos, confirming the author's hypothesis. Both axes on the RP show time (or number of iteration), while the colour scale represents the distance from a point on the diagonal to all other points on the trajectory. Is worth to say, the 

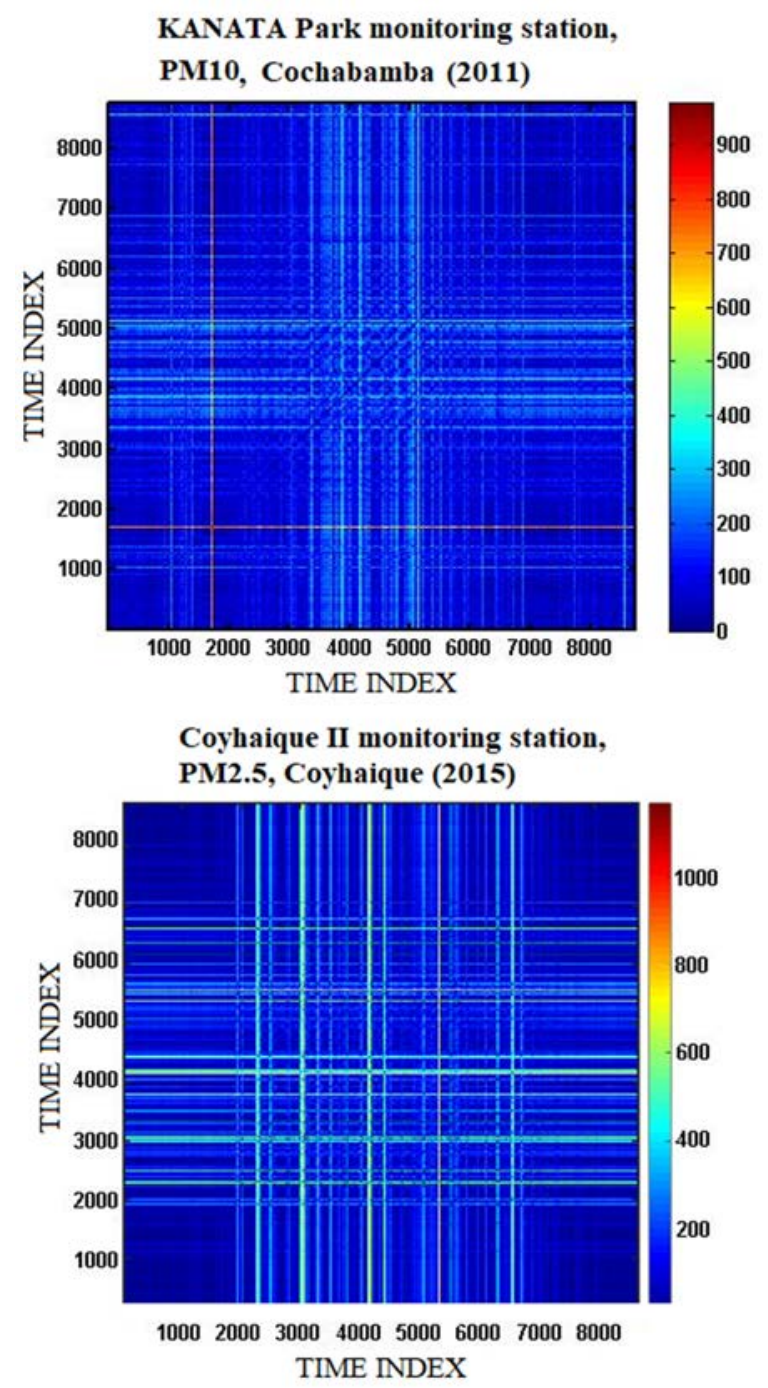

Figure 4: Recurrence plots of $\mathrm{PM}_{2.5}$ for Coyhaique monitoring station from South of Chile, and $\mathrm{PM}_{10}$ monitoring stations in Cochabamba urban area.

colour of each point represents how similar the $\mathrm{x}$ time is to $\mathrm{y}$ time in terms of $\mathrm{PM}_{2.5}$ or $\mathrm{PM}_{10}$. Thus, the colour intensity allows for estimation of the strength of an attractor.

\subsection{Wavelet spectrum}

Wavelet spectrum and global amplitude for the polluted cities under study was applied, where their spectral descomposition was developed in time-frecuency through Morlet's wavelet transform and their global amplitud of wavelets in time and the energy concentrated around the most importants peaks. Here the results are presented for only one station for $\mathrm{PM}_{10}$ and $\mathrm{PM}_{2.5}$, because for the other stations the results are similar. 
The time series of Coyhaique I monitoring station for $\mathrm{PM}_{2.5}$ shows the evolution of this pollutant from March 2013 to August 2016. From Fig. 5 it is observed that the amplitude exceeds the value of $1000\left(\mu \mathrm{g} \mathrm{m}^{-3}\right)^{2}$ in winter. The blue contours show low powers close to zero, while the more intense red colours correspond to power zones greater than $2^{15}\left(\mu \mathrm{g} \mathrm{m}^{-3}\right)^{2}$. The black line represents the cone of influence (COI) where data located outside cannot be interpreted due to edge effects. From Fig. 5 it can be observed that the time series is modulated by the annual cycle, which presents a power between $2^{12}$ and $2^{15}\left(\mu \mathrm{g} \mathrm{m}^{-3}\right)^{2}$. There is also a high activity in the winter season, which extends from April to September of each year. However, there is a decrease in the summer season (between October and March) with a power between $2^{3}$ and $\left.2^{6}(\mu \mathrm{g} \mathrm{m})^{-3}\right)^{2}$. Here a high activity is observed in the half-day and daily cycle, which remains high throughout the month. The power averaged over time shows three important peaks: annual cycle, half-day cycle and daily cycle.

The time series of the Kanata Park monitoring station for $\mathrm{PM}_{10}$ shows the evolution of this pollutant from March 2009 until the end of 2012. It is observed in winter that the amplitudes reach values of up to $600\left(\mu \mathrm{g} \mathrm{m}^{-3}\right)^{2}$ every year under study. The blue contours show low powers close to zero, while the more intense red colours correspond to power zones greater than $2^{15}\left(\mu \mathrm{g} \mathrm{m}^{-3}\right)^{2}$. The black line represents the influence cone where data located outside it cannot be interpreted due to edge effects. From Fig. 6 it can be observed that the time series is modulated by the annual cycle, which presents a power between $2^{9}$ and $2^{12}(\mu \mathrm{g}$ $\left.\mathrm{m}^{-3}\right)^{2}$. There is also a high activity in the winter season, which extends from April to September of each year. However, there is a decrease in the summer season (between October and March) with a power between $2^{4}$ and $\left.2^{6}(\mu \mathrm{g} \mathrm{m})^{-3}\right)^{2}$. Here a high activity is observed in the half-day and daily cycle, which remains high throughout the month.

Shen et al. [32] have applied this methodology to Air pollution index (API) records in Nanjing, China from January 2001 to December 2012, by means of Morlet wavelet transformation, founding similar result to the author.
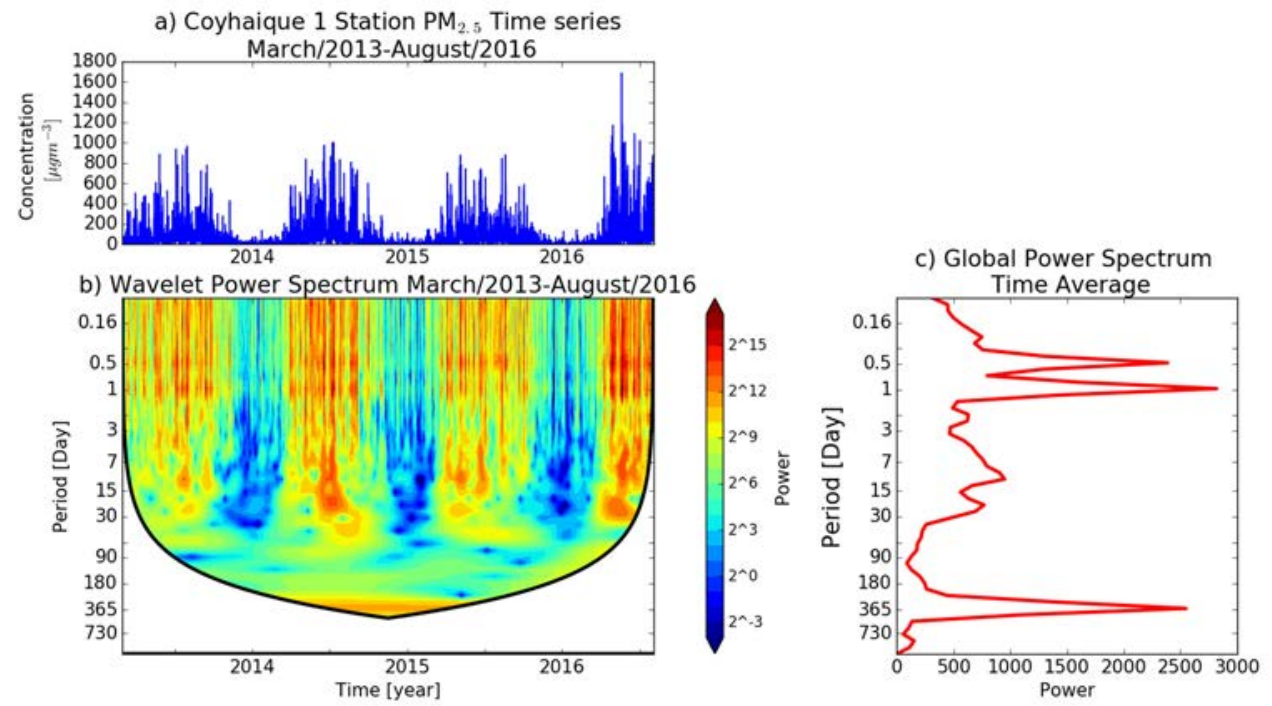

Figure 5: Contour plots of wavelet coefficient for $\mathrm{PM}_{2.5}$ at Coyhaique I monitoring station. 

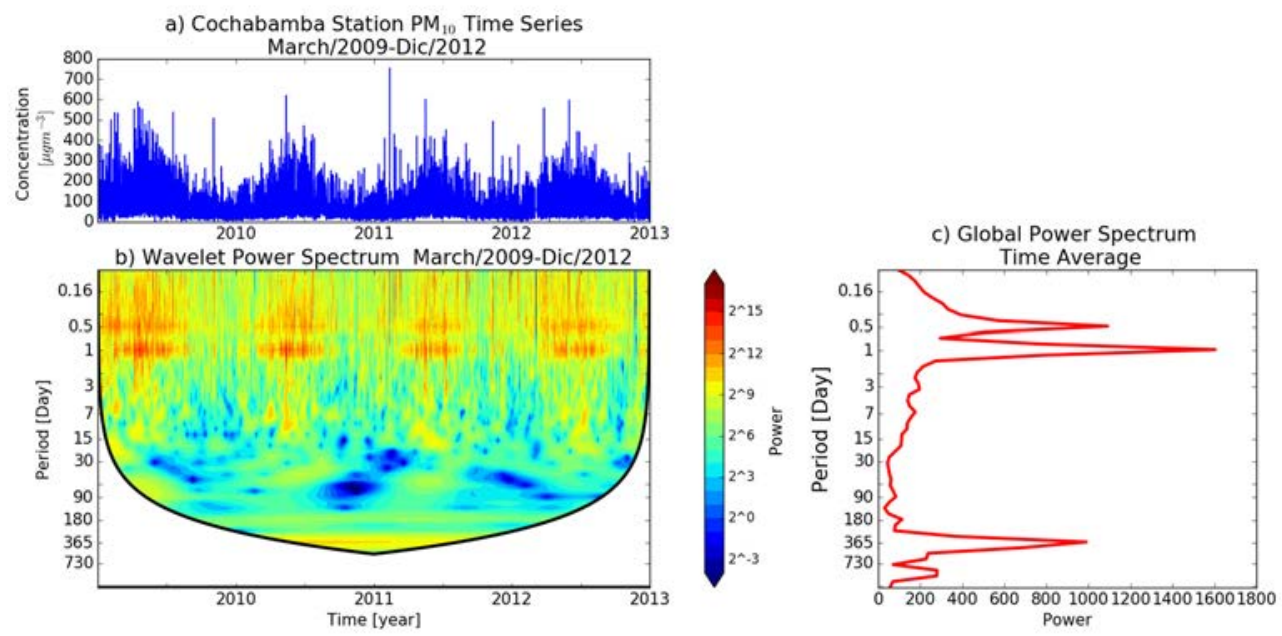

Figure 6: Contour plots of wavelet coefficient for $\mathrm{PM}_{10}$ at Kanata Park monitoring station.

\section{CONCLUSIONS}

In this study, nonlinear analysis of $\mathrm{PM}_{2.5}$ and $\mathrm{PM}_{10}$ data observed at three sites in three midsized cities from South of Chile was performed to characterize the time series. The analysis of the $\mathrm{PM}_{2.5}$ and $\mathrm{PM}_{10}$ time series shows its chaotic behaviour using phase portrait and recurrence plots. It is suggested to perform a quantitative study using a methodology similar to the recurrence plots, as recurrence quantification analysis (RQA). On the other hand, contour plots of wavelet coefficients for the $\mathrm{PM}_{2.5}$ and $\mathrm{PM}_{10}$ time series shows the periodic trend for all $\mathrm{PM}_{2.5} / \mathrm{PM}_{10}$ time series concentrations in study. The global power spectrum shows three important peaks: annual, daily and half-day cycle in all $\mathrm{PM}_{2.5} / \mathrm{PM}_{10}$ concentrations.

\section{ACKNOWLEDGEMENTS}

The support from Facultad de Ingeniería, Universidad Católica de la Ssma. Concepción, is gratefully acknowledged. The author acknowledge prof. Patricio Pérez J. for their professional advice. The author also acknowledge the support from Universidad Católica de la Ssma. Concepción through DIN Project number 13/2016. Finally, the author thanks Miss Evelin Medina M. and Mr. Rodrigo Valenzuela M. for making some calculations from their expertise.

\section{REFERENCES}

[1] Cifuentes, L.A., Vega, J., Köpfer, K. \& Lave, L.B., Effect of fine fraction of particulate matter versus the coarse mass and other pollutants on daily mortality in Santiago Chile. Journal of the Air \& Waste Management Association, 50, pp. 1287-1298, 2000.

[2] Schwartz, J. \& Neas, L.M., Fine particles are more strongly associated tan coarse particles with acute respiratory health effects in school children. Epidemiology, 11, pp. 6-10, 2000.

[3] Schwartz, J., Laden, F. \& Zanobetti, A., The concentration-response relation between $\mathrm{PM}_{2.5}$ and daily deaths. Environmental Health Perspective, 110(10), pp. 1025-1029, 2002. 
[4] Brook, R.D. et al., Particulate Matter Air Pollution and Cardiovascular Disease: An Update to the Scientific Statement From the American Heart Association. Circulation, 121, pp. 2331-2378, 2010. DOI: 10.1161/CIR.0b013e3181dbece1.

[5] Lee, B., Kim, B. \& Lee, K., Air pollution exposure and cardiovascular disease. Toxicological research, 30(2), pp. 71-75, 2014. DOI: 10.5487/TR.2014.30.2.071.

[6] Pope III, C.A. et al., Lung cancer, cardiopulmonary mortality and long-term exposure to fine particulate air pollution. Journal of the American Medical Association, 287, pp. 1132-1141, 2002.

[7] Ilabaca, M., Olaeta, I., Campos, E., Villaire, J., Tellez-Rojo, M.M. \& Romieu, I., Association between levels of fine particulate and emergency visits for pneumonia and other respiratory illness among children in Santiago, Chile. Journal of the Air \& Waste Management Association, 49(9), pp. 154-163, 1999.

[8] Cakman, S., Dales, R.E. \& Blanco, C., Air pollution and mortality in Chile: susceptibility among the elderly. Environmental Health Perspective, 115(4), pp. 524527,2007

[9] WHO, Air Quality Guidelines. Global Update 2005, Particulate Matter, Ozone, Nitrogen Dioxide and Sulfur Dioxide, 2006. ISBN: 9289021926.

[10] Norma Primaria de Calidad Ambiental para material Particulado Fino Respirable MP2, 5. Diario Oficial de la República de Chile, $\mathrm{n}^{\circ} 39.955$, Cuerpo 1, lunes 9 de mayo de 2011, 24, Ministerio del Medio Ambiente (MMA), 2011.

[11] Salini, G.A., Particulatte matter analysis from mid-sized cities in the south of Chile. INGE CUC, 10(1), pp. 97-108, 2014.

[12] Reglamentación Ley del Medioambiente, $N^{\circ} 1333$, Gaceta Oficial del Gobierno de Bolivia, Gaceta Oficial de Bolivia, 129 pp., 1992.

[13] Salini, G.A. \& Medina, E., Estudio sobre la dinámica temporal de material particulado $\mathrm{PM}_{10}$ emitido en Cochabamba, Bolivia. Revista Internacional de Contaminación Ambiental, 33(3), pp. 437-448, 2017. DOI: 10.20937/RICA.2017.33.03.07.

[14] Sprott, J.C., Chaos and Time-Series Analysis, Oxford University Press: Oxford, UK, p. 528, 2003.

[15] Salini, G.A. \& Pérez, P., Estudio de series temporales de contaminación ambiental mediante técnicas de redes neuronales artificiales. Ingeniare, Revista Chilena de Ingeniería, 14(3), pp. 284-290, 2006. DOI: 10.4067/S0718-33052006000200012.

[16] Salini, G.A. \& Pérez, P., A study of the dynamic behaviour of fine particulate matter in Santiago, Chile. Aerosol \& Air Quality Research, 15, pp. 154-165, 2015. DOI: 10.4209/aaqr.2013.10.0323.

[17] SINCA (Chilean Air Quality Information System), Online. https://sinca.mma.gob.cl/. Accessed on: 20 Mar. 2018.

[18] MMA (Chilean Ministry of the Environment, Online. https://sinca.mma.gob.cl/ index.php. Accessed on: 20 Mar. 2018.

[19] Red MoniCA, Informe nacional de la calidad del aire 2008-2009, Ministerio del Medio Ambiente y Agua: La Paz, Bolivia, p. 35, 2010.

[20] MMAyA. (Bolivian Ministry of Environment and Water), www.mmaya.gob.bo/. Accessed on: 20 Mar. 2018.

[21] Mallat, S.A., Wavelet tour of signal processing, 3rd ed., The Sparse Way, Academic Press, London, 1998.

[22] Torrence, C. \& Compo, G.P., A practical guide to wavelet analysis. Bulletin of the American Meteorological Society, 79, pp. 61-78, 1998. 
[23] Takens, F., Detecting strange attractors in turbulence. Dynamical Systems and Turbulence, Lecture Notes in Mathematics, eds D.A. Rand \& L.S. Young, SpringerVerlag: Berlin, pp. 366-381, 1981.

[24] Lee, C.K. \& Lin, S.C., Chaos in air pollutant concentration (APC) time series. Aerosol and Air Quality Research, 8(4), pp. 381-391, 2008.

[25] Yu, B., Huang, C., Liu, Z., Wang, H. \& Wang, I., A Chaotic analysis on air pollution index over the past ten years in Lanzhou, northwest China. Stochastic Environmental Research and. Risk Assessment, 25, pp. 643-653, 2011. DOI: 10.1007/s00477-0110471-y.

[26] Eckmann, J.P., Kamphorst, A.O. \& Ruelle, D., Recurrence plots of dynamical systems. Europhysics Letters, 4(9), pp. 973-977, 1987.

[27] Strozzi, F., Zaldivar, J.M. \& Zbilut, J.P., Recurrence quantification analysis and state space divergence reconstruction for financial time series analysis. Physica A, 376(1), pp. 487-499, 2007.

[28] Marwan, N., How to avoid potential pitfalls in recurrence plots-based data analysis. International Journal of Bifurcation and Chaos, 21(4), pp. 1003-1017, 2011. DOI: 10.1142/S0218127411029008.

[29] Yang, H., Multiscale recurrence quantification analysis of spatial vectorcardiogram (VCG) signals. IEEE Transactions on Biomedical Engineering, 58(2), pp. 339-347, 2011. DOI: 10.1109/TBME.2010.2063704.

[30] Aceves-Fernandez, M.A., Pedraza-Ortega, J.C., Sotomayor-Olmedo, A., RamosArreguín, J.M., Vargas-Soto, J.E. \& Tovar-Arriaga, S., Analysis of key features of non-linear behaviour using recurrence plots. Case study: urban pollution at Mexico City. Journal of Environmental Protection, 3, pp. 1147-1160, 2012. DOI: 10.4236/ jep.2012.329133.

[31] Chelani, A.B., Singh, R.N. \& Devotta, S., Nonlinear dynamical characterization and prediction of ambient nitrogen dioxide concentration. Water, Air and Soil Pollution, 166(1)-(4), pp. 121-138, 2005. DOI:10.1007/s11270-005-7384-7.

[32] Shen, C.-H., Huang, Y. \& Yan, Y.-N., An analysis of multifractal characteristics of API time series in Nanjing, China. Physica A, 451, pp. 171-179, 2016. DOI: 10.1016/ j.physa.2016.01.061. 